\title{
Simulation of denitrification and ozone loss for the Arctic winter 2002/2003
}

\author{
J.-U. Grooß ${ }^{1}$, G. Günther ${ }^{1}$, R. Müller ${ }^{1}$, P. Konopka ${ }^{1}$, S. Bausch ${ }^{1}$, H. Schlager ${ }^{2}$, C. Voigt $^{2}$, C. M. Volk ${ }^{3}$, and G. C. Toon ${ }^{4}$ \\ ${ }^{1}$ Institut für Chemie und Dynamik der Geosphäre I: Stratosphäre (ICG I), Forschungszentrum Jülich, Jülich, Germany \\ ${ }^{2}$ Institut für Physik der Atmosphäre, DLR Oberpfaffenhofen, Germany \\ ${ }^{3}$ Institut für Meteorologie und Geophysik, Universität Frankfurt, Germany \\ ${ }^{4}$ Jet Propulsion Laboratory, California Institute of Technology, Pasadena, CA, USA
}

Received: 21 October 2004 - Published in Atmos. Chem. Phys. Discuss.: 6 December 2004

Revised: 22 April 2005 - Accepted: 9 May 2005 - Published: 15 June 2005

\begin{abstract}
We present simulations with the Chemical Lagrangian Model of the Stratosphere (CLaMS) for the Arctic winter 2002/2003. We integrated a Lagrangian denitrification scheme into the three-dimensional version of CLaMS that calculates the growth and sedimentation of nitric acid trihydrate (NAT) particles along individual particle trajectories. From those, we derive the $\mathrm{HNO}_{3}$ downward flux resulting from different particle nucleation assumptions. The simulation results show a clear vertical redistribution of total inorganic nitrogen $\left(\mathrm{NO}_{\mathrm{y}}\right)$, with a maximum vortex average permanent $\mathrm{NO}_{\mathrm{y}}$ removal of over $5 \mathrm{ppb}$ in late December between 500 and $550 \mathrm{~K}$ and a corresponding increase of $\mathrm{NO}_{\mathrm{y}}$ of over 2 ppb below about $450 \mathrm{~K}$. The simulated vertical redistribution of $\mathrm{NO}_{\mathrm{y}}$ is compared with balloon observations by MkIV and in-situ observations from the high altitude aircraft Geophysica. Assuming a globally uniform NAT particle nucleation rate of $7.8 \times 10^{-6} \mathrm{~cm}^{-3} \mathrm{~h}^{-1}$ in the model, the observed denitrification is well reproduced.

In the investigated winter $2002 / 2003$, the denitrification has only moderate impact $(\leq 14 \%)$ on the simulated vortex average ozone loss of about $1.1 \mathrm{ppm}$ near the $460 \mathrm{~K}$ level. At higher altitudes, above $600 \mathrm{~K}$ potential temperature, the simulations show significant ozone depletion through $\mathrm{NO}_{\mathrm{x}}-$ catalytic cycles due to the unusual early exposure of vortex air to sunlight.
\end{abstract}

\section{Introduction}

During the Arctic winter 2002/2003, an extensive coordinated US-European measurement campaign (SOLVE II/VINTERSOL) was carried out to investigate a variety of open

Correspondence to: J.-U. Grooß

(j.-u.grooss@fz-juelich.de) questions in polar stratospheric research. Within this campaign in-situ and remote measurements from balloons, high and low flying aircraft, satellite and ground stations were collected. Most measurements were performed from Kiruna, Sweden $\left(68^{\circ} \mathrm{N}\right)$.

The winter 2002/2003 was characterized by extremely low temperatures in early winter (Naujokat and Grunow, 2003; Tilmes et al., 2003) that are necessary for polar stratospheric cloud (PSC) formation. Around 18 November, temperatures fell below the threshold temperature $\mathrm{T}_{\mathrm{NAT}}$ below which NAT (Nitric Acid Trihydrate) particles can exist (Hanson and Mauersberger, 1988). In December there were recordlarge areas with temperatures below $\mathrm{T}_{\mathrm{NAT}}$. During this time PSCs were observed both from ground based LIDAR and from satellite (Spang et al., 2005). In mid-January, a major warming led to the rise of temperatures above $\mathrm{T}_{\mathrm{NAT}}$ so that PSCs disappeared. In early February the vortex stabilized again and low temperatures necessary for PSC formation were present again for a few days. Finally the vortex broke down in late April.

In this study, we focus on the simulation of denitrification throughout the winter. The importance of denitrification for polar stratospheric chemistry has been known for a long time (Fahey et al., 1990; Waibel et al., 1999). However, only in the last years the processes involved in denitrification have become clearer. In-situ observations of PSCs in the Arctic winter 1999/2000 (Fahey et al., 2001) have led to the discovery of large $\mathrm{HNO}_{3}$ containing PSC particles up to $20 \mu \mathrm{m}$ diameter with low number density of about $10^{-4} \mathrm{~cm}^{-3}$. Due to this low number density, those particles can grow to large sizes within a few days, sediment and transport significant amounts of $\mathrm{HNO}_{3}$ downwards, consequently leading to denitrification (Carslaw et al., 2002).

(C) 2005 Author(s). This work is licensed under a Creative Commons License. 
In addition to the mode with low particle number density, smaller NAT particles at higher number densities of about $10^{-3} \mathrm{~cm}^{-3}$ have frequently been observed in the Arctic stratosphere (Deshler et al., 2003; Larsen et al., 2004; Fahey et al., 2001). Because the settling velocity of a $3 \mu \mathrm{m}$ diameter NAT particle is about $90 \mathrm{~m}$ per day on the $500 \mathrm{~K}$ level, the smaller particles do not sediment significantly. Instead, the growth of other NAT particles is reduced in the presence of such higher particle number densities because those particles reduce the available $\mathrm{HNO}_{3}$ in the gas phase due to uptake into the particles until equilibrium between particles and gas phase is reached. At particle number densities above $10^{-3} \mathrm{~cm}^{-3}$, the equilibrium is reached within less than one day (B. Luo, personal communication, 2004).

The vertical redistribution of $\mathrm{HNO}_{3}$ due to the sedimentation of the large NAT particles has an important impact on stratospheric chemistry. Firstly, the reactive surface and volume of the solid and liquid PSCs and indeed the threshold temperature for PSC existence depend on the available $\mathrm{HNO}_{3}$ in the gas phase. Secondly, a loss of $\mathrm{HNO}_{3}$ due to denitrification implies a slower increase of $\mathrm{NO}_{\mathrm{x}}\left(=\mathrm{NO}+\mathrm{NO}_{2}\right)$ at a later time as $\mathrm{HNO}_{3}$ is the major reservoir of $\mathrm{NO}_{\mathrm{x}}$. In the Arctic, the reaction of $\mathrm{NO}_{2}$ with $\mathrm{ClO}$ is mainly responsible for the chlorine deactivation at the end of the PSC period. Thus, the vertical redistribution of $\mathrm{HNO}_{3}$ influences both chlorine activation and deactivation. Model simulations that aim to reproduce ozone realistically must therefore include a realistic denitrification scheme. The nucleation process of NAT particles at low number densities has not yet been identified. Larger number densities of NAT particles could nucleate on ice in lee-wave events (Luo et al., 2003; Voigt et al., 2003; Carslaw et al., 2002). Recent observations (Voigt et al., 2005; Larsen et al., 2004) show that NAT particles also form at short timescales of about one day at temperatures above the ice frost-point. Tabazadeh et al. (2002) suggested a surface nucleation mechanism, but the nucleation rate must be more than an order of magnitude lower to explain the particle observations (Larsen et al., 2004). Studies for the winter 1999/2000 use a globally uniform, volume averaged nucleation rate independent of temperature and achieve realistic denitrification (Carslaw et al., 2002; Mann et al., 2002, 2003). The NAT nucleation rates derived from observations in the winter 2002/2003 (Voigt et al., 2005; Larsen et al., 2004) are higher compared to the uniform nucleation rate used by Carslaw et al. (2002) in their study of denitrification in the winter 1999/2000. Another approach to explain the large NAT particle mode employs a localized nucleation on ice particles at the bottom of a so-called mother cloud (Fueglistaler et al., 2002). However, since observations show that NAT particles can nucleate without the mother cloud mechanism (Voigt et al., 2005), we follow here the first assumption, i.e. a globally uniform, volume averaged nucleation rate independent of temperature.

The remaining uncertainties especially with respect to the nucleation process cannot be resolved here. The aim of this study is to find combinations of parameters using the available knowledge of NAT nucleation that allow to simulate the observed denitrification.

\section{Model description}

Current chemistry transport model (CTM) simulations taking into account vertical $\mathrm{NO}_{\mathrm{y}}$ redistribution by sedimentation of large NAT particles use a combination of a Lagrangian particle model with an Eulerian CTM (Carslaw et al., 2002; Mann et al., 2003). Here, we present simulations in which both the NAT particles and the chemistry are simulated in a Lagrangian way.

The Chemical Lagrangian Model of the Stratosphere (CLaMS) was initially developed as a two-dimensional Lagrangian chemical transport model on isentropic surfaces (McKenna et al., 2002b,a). Recently, it was further developed as a full three-dimensional model (Konopka et al., 2004). In an earlier version of the model, denitrification was parameterized in a way that only the loss of $\mathrm{HNO}_{3}$ is described with a rate depending on the assumed size of the PSC particles (Grooß et al., 2002). Here, we use a more realistic approach that takes into account the $\mathrm{HNO}_{3}$ flux due to sedimenting large PSC particles and also considers the $\mathrm{HNO}_{3}$ increase due to particle evaporation.

The calculation of growth and evaporation of large NAT particles is carried out following the procedure described in detail by Carslaw et al. (2002). The growth of each particle leads to a change of its sedimentation velocity, which is computed with a time-step of $30 \mathrm{~min}$. All particles (hereafter called particle boxes, to emphasize the technical character of the term and to avoid misinterpretation and confusion) are advected horizontally on isentropic levels using the background wind fields. The vertical motion is calculated using the sedimentation velocity only. The particle boxes are advected until the particles have evaporated completely. New particle boxes are nucleated every $24 \mathrm{~h}$ within 32 isentropic layers between 400 and $700 \mathrm{~K}$ north of $50^{\circ} \mathrm{N}$ at locations with $\mathrm{T}<\mathrm{T}_{\mathrm{NAT}}$ with a mean distance of $67 \mathrm{~km}$, the density of particle boxes being a factor of about 4 higher than the density of the CLaMS air parcels for which the chemistry is calculated. This was done to assure that in areas where particle boxes occur, all CLaMS air parcels have the chance to interact with at least one particle box.

Each particle box represents a much higher number of real atmospheric particles to keep the number of simulated particle boxes computationally manageable. Similar to Carslaw et al. (2002), a scaling factor in form of a number density is applied during the interaction between the particle boxes and the background chemistry. An effective nucleation rate can be calculated from the product of the number density of atmospheric particles in the newly added particle boxes and the ratio of the particle boxes and the air parcels, divided by the CLaMS time step (24h). 
The interaction between the particle boxes and the background chemistry is managed by first determining the three nearest neighboring air parcels within the layers above and below the current position of every particle box, thus creating a polyhedron containing the particle box. Nitric acid and water vapor being taken up or released during growth or evaporation, respectively, are then taken from or added to these six nearest air parcels using a distance depending weight. The impact of the interaction between particle boxes and air parcels is then determined by assigning a particle number density (the above mentioned scaling factor) to each particle box to compute the exchange of nitric acid and water vapor.

In this context it should be noted, that the density of the air parcels within each isentropic layer are not conserved during the simulation due to the properties of the mixing algorithm. This was also taken into account when calculating the mass exchange between CLaMS air parcels and particle boxes by applying an appropriate correction factor.

In sensitivity simulations, we changed the NAT nucleation rate in the model to investigate its impact on the resulting denitrification. In the standard case, we use a constant effective nucleation rate of $7.8 \times 10^{-6} \mathrm{~cm}^{-3} \mathrm{~h}^{-1}$ at all locations where $\mathrm{T}<\mathrm{T}_{\mathrm{NAT}}$, because this results in the best comparison with the observations (see below). This is about the same as the rate reported by Voigt et al. (2005) and a factor of 3.2 lower than the rate suggested by Larsen et al. (2004). The nucleation rate is about a factor of 2.7 larger than used by Carslaw et al. (2002) for the winter 1999/2000.

The mode with high particle number density was not generated by the sedimentation scheme. To achieve this mode we used the microphysics module already implemented in CLaMS (Carslaw et al., 1995; McKenna et al., 2002a), in which a particle mode with given number density (here: $0.003 \mathrm{~cm}^{-3}$ ) can nucleate upon cooling from liquid aerosol at a certain supersaturation with respect to NAT or from sulfuric acid tetrahydrate (SAT). This critical supersaturation of $\mathrm{HNO}_{3}$ over NAT was varied and was set to 30 in the reference simulation corresponding to a temperature about $5 \mathrm{~K}$ below $\mathrm{T}_{\mathrm{NAT}}$. NAT formation from SAT is possible in this scheme but is not allowed in the reference simulation. Sedimentation of this mode is not considered. Therefore there are three possibilities to change the denitrification parameterization: A change of the rate of nucleation for the mode with low particle density, a change of the critical supersaturation to form the mode with high particle density, or a change whether or not NAT particles can form on SAT upon cooling. The SAT particles in the last case originate from previously evaporated NAT particles.

In the current simulation we use a horizontal resolution of $100 \mathrm{~km}$ in the area north of $40^{\circ} \mathrm{N}$ and $300 \mathrm{~km}$ between the equator and $40^{\circ} \mathrm{N}$ for the air parcels. The vertical model domain is between 350 and $900 \mathrm{~K}$ potential temperature divided into 30 levels.

\section{Initialization and boundary conditions}

The presented CLaMS simulation was started for 17 November 2002 to ensure that it starts before the onset of PSC formation that is also the begin of denitrification. The chemical composition of the air parcels in the model domain was derived differently for the individual chemical species depending on the available data.

The initialization of $\mathrm{O}_{3}$ was based on the MIPASENVISAT data from 16 and 17 November 2002. Here, we used the near-real-time data version of the MIPAS data provided by the European Space Agency (ESA). Data profiles for which the retrieval is potentially disturbed due to PSCs are excluded from the data set using the cloud index defined by Spang et al. (2005). From the observation locations and times trajectories on 19 isentropic levels between 350 and $2000 \mathrm{~K}$ were started to determine the locations of the observed air masses at the synoptic time 17 November 12:00 UT. These data then were gridded onto a regular $2^{\circ} \times 6^{\circ}$ latitude-longitude grid on each level. Points within $440 \mathrm{~km}$ distance of a grid point contributed to it with different weights taking into account its distance and its given relative accuracy. $\mathrm{CH}_{4}$ was initialized using HALOE satellite and MkIV balloon data. Since HALOE observations (Russell et al., 1993) are available much less frequently than MIPAS data, a different method and a longer time interval was used. The HALOE $\mathrm{CH}_{4}$ observations of November and December 2002 were averaged into equivalent latitude bins on the different isentropic levels. Since HALOE barely sampled the vortex during this time the data were combined with vortex $\mathrm{CH}_{4}$ observations on 16 December 2002 obtained by MkIV (Toon et al., 1999). Correlations of $\mathrm{CH}_{4}$ with other compounds $\left(\mathrm{N}_{2} \mathrm{O}, \mathrm{Cl}_{\mathrm{y}}, \mathrm{Br}_{\mathrm{y}}\right)$ were used as in $\mathrm{Grooß}$ et al. (2002), with the exception that $\mathrm{Br}_{\mathrm{y}}$ was increased by $10 \%$ to maximum mixing ratios of about $20 \mathrm{ppt}$. Total reactive nitrogen $\left(\mathrm{NO}_{\mathrm{y}}\right)$ was initialized using the correlation with $\mathrm{N}_{2} \mathrm{O}$ given by Popp et al. (2001). For air parcels with $\mathrm{N}_{2} \mathrm{O}$ mixing ratios between 1 and $33 \mathrm{ppb}$ the correlation was extended here on the basis of the same data (MkIV balloon profile in December 1999) using the following relation:

$\left[\mathrm{NO}_{\mathrm{y}}\right]=11.7+4.49 \times \ln \left[\mathrm{N}_{2} \mathrm{O}\right]-0.948 \times\left(\ln \left[\mathrm{N}_{2} \mathrm{O}\right]\right)^{2},(1)$ where $\mathrm{NO}_{\mathrm{y}}$ and $\mathrm{N}_{2} \mathrm{O}$ mixing ratios are given in ppb.

The sulfate background aerosol in the model is given as $\mathrm{H}_{2} \mathrm{SO}_{4}$ equivalent gas phase mixing ratio. Its altitude dependence (given in ppb) was derived from a detailed study (Bausch et al., manuscript in preparation) to be

$$
\begin{aligned}
{\left[\mathrm{H}_{2} \mathrm{SO}_{4}\right] } & =1.21 \times 10^{-8} \theta^{3}-3.67 \times 10^{-5} \theta^{2} \\
& +2.96 \times 10^{-2} \theta-7.97,
\end{aligned}
$$

for the potential temperature range $450 \mathrm{~K} \leq \theta \leq 900 \mathrm{~K}$. At the upper boundary of the model domain $(900 \mathrm{~K})$, also the chemical composition of the air parcels was prescribed derived in a similar way from the satellite data. At the lower boundary $(350 \mathrm{~K})$, the chemical composition of the air parcels was 


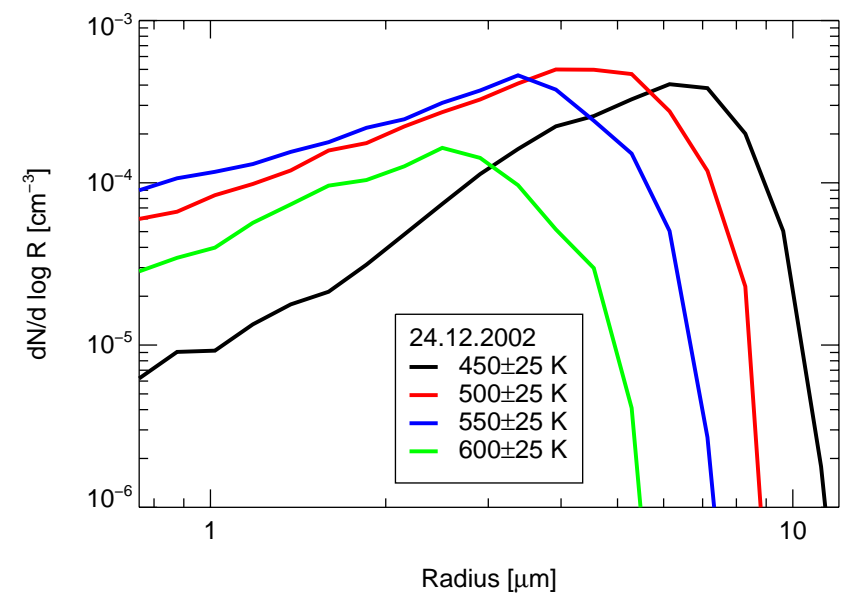

Fig. 1. Simulated average size distribution of low particle number density mode on 24 December 2002. Shown is the distribution of particle radius $\mathrm{R}$ for the area of NAT particle existence converted to $\mathrm{dN} / \mathrm{d} \log \mathrm{R}$ for different potential temperature ranges as indicated in the legend.

not changed during the run. This was done because there is general downward motion in the vortex over the winter and with this method the airmasses near the lower boundary stay self-consistent.

Similar as the initialization, the boundary conditions at the upper boundary of the model domain were determined. At the upper boundary $(900 \mathrm{~K})$, ENVISAT-MIPAS data for $\mathrm{O}_{3}$ and $\mathrm{CH}_{4}$ were averaged over equivalent latitude bins for the simulation time every half month within 5 days. From that data, the same correlations as above were used to determine $\mathrm{N}_{2} \mathrm{O}, \mathrm{Cl}_{\mathrm{y}}, \mathrm{Br}_{\mathrm{y}}$, and $\mathrm{NO}_{\mathrm{y}}$. Species not mentioned and the partitioning within the families were taken from the Mainz 2-D photochemical model (Grooß, 1996).

The ozone mixing ratio needed for the radiative transfer code (Becker et al., 2000) that determines the photolysis rates has been taken from a climatology based on HALOE measurements as function of latitude, pressure and month (Grooß and Russell, 2005).

\section{Denitrification}

For the current simulation, the downward $\mathrm{NO}_{\mathrm{y}}$ flux was very variable depending on temperature. The maximum number of about 145000 particle boxes was simulated on 24 December. To derive a size distribution of NAT particles from the model results one has to average over a large volume and has to weight it by the ratio of present particle boxes to air parcels. The simulated particle size distribution for 24 December is shown in Fig. 1 for the whole area where NAT particles exist divided into different potential temperature regions. It is evident that at the lower levels larger particles were simulated since they did have more time to grow. It is

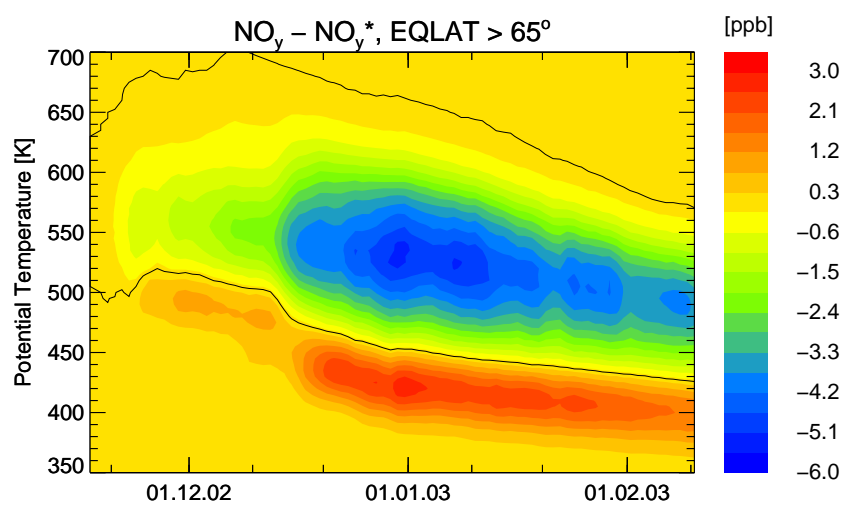

Fig. 2. Redistribution of $\mathrm{NO}_{\mathrm{y}}$ as function of time and potential temperature from the reference simulation $\left(J=7.8 \times 10^{-6} \mathrm{~cm}^{-3} \mathrm{~h}^{-1}\right)$. Shown is the average over equivalent latitude range $65-90^{\circ} \mathrm{N}$ for the period 17 November 2002 to 10 February 2003. The zero contour is displayed as a black line.

also evident that with this parameterization, no high particle number density mode at low sizes is present. This is the reason why the high particle number density mode was added separately to the code.

Figure 2 shows the simulated $\mathrm{NO}_{\mathrm{y}}$ change due to the sedimentation of the large NAT particles averaged over equivalent latitude range $65-90^{\circ} \mathrm{N}$ for the reference simulation. The unperturbed $\mathrm{NO}_{\mathrm{y}}^{*}$ was simulated by a passive tracer that was initialized identically as $\mathrm{NO}_{\mathrm{y}}$ and that was then advected and mixed without chemistry and denitrification. The maximum denitrification of over 5 ppb is reached in early January. After that time, no significant additional denitrification was simulated and the denitrified air masses were only advected further. Also clearly visible is the re-nitrification at lower levels caused by the evaporation of the NAT particles. The diabatic descent within the polar vortex causes the downward motion of the denitrification peak. The mixing ratio increase at the re-nitrification altitudes is lower than the mixing ratio decrease at denitrification altitudes, because the total mass of sedimented $\mathrm{HNO}_{3}$ should be conserved and the pressure increases with decreasing altitude. Visible is also the very small chemical production of $\mathrm{NO}_{\mathrm{y}}$ through the reaction of $\mathrm{N}_{2} \mathrm{O}$ with $\mathrm{O}\left({ }^{1} \mathrm{D}\right)$ in early February above $600 \mathrm{~K}$.

Figure 3 shows examples for simulated $\mathrm{NO}_{\mathrm{y}}$ change on 19 January for the $425 \mathrm{~K}$ and $450 \mathrm{~K}$ levels. Note that the simulated $\mathrm{NO}_{\mathrm{y}}$ redistribution is very inhomogeneous in space at that time. This is due to the temperature threshold of the process. At locations with temperatures just above $\mathrm{T}_{\mathrm{NAT}}$, all NAT particles evaporate relatively fast, which leads to strong re-nitrification, while possibly particles at close by locations with slightly lower temperatures can sediment further down.

In the following we show comparisons of the simulated denitrification with observations from MkIV and the Geophysica. 

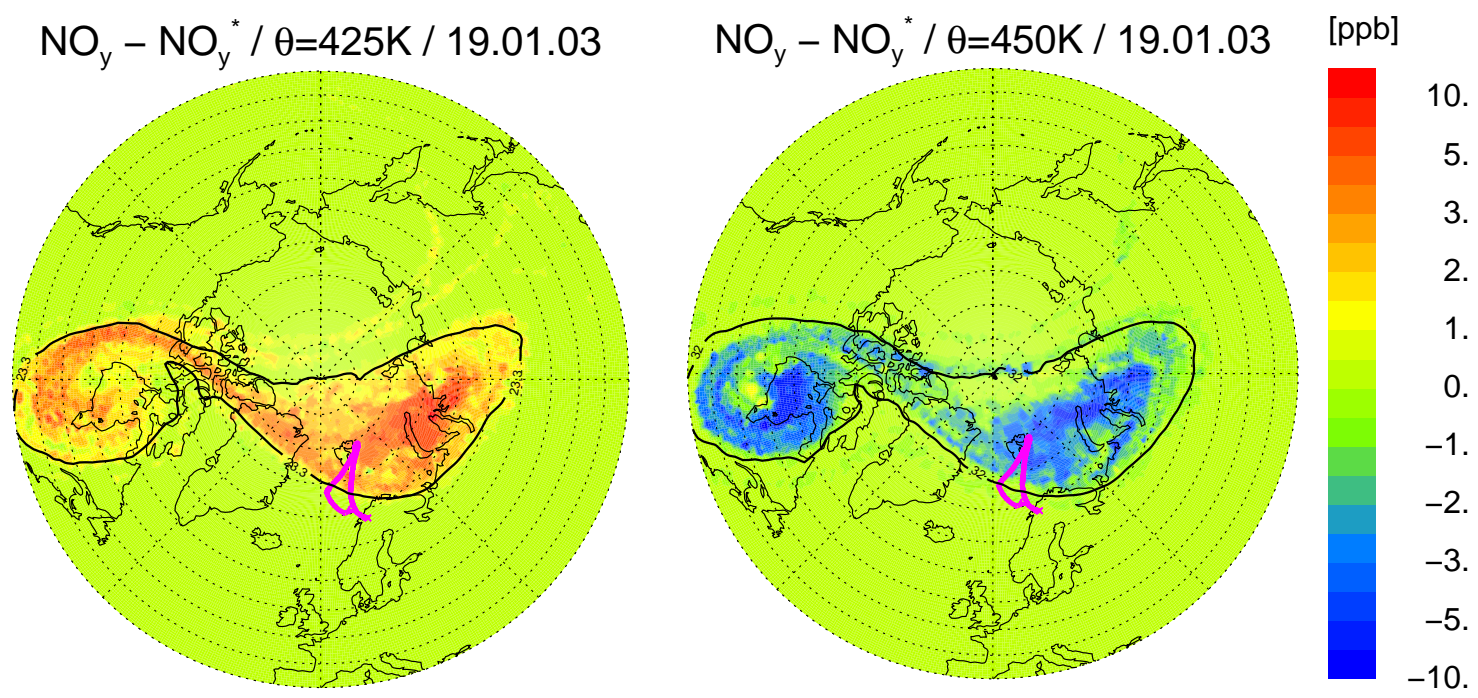

Fig. 3. Simulated redistribution of $\mathrm{NO}_{\mathrm{y}}$ on 19 January 2003 for the potential temperature levels $425 \mathrm{~K}$ (left) and $450 \mathrm{~K}$ (right). The pink line indicates the Geophysica flight path (transformed to synoptic 12:00 UT locations). The black line marks the vortex edge.

\subsection{Early denitrification observed by MkIV}

On 16 December 2002, the MkIV experiment on board the OMS remote balloon gondola measured $\mathrm{N}_{2} \mathrm{O}$ and all major $\mathrm{NO}_{\mathrm{y}}$ compounds among many other species (Toon et al., 1999). At that time, already an onset of denitrification was both observed and simulated. These data are an important constraint for the denitrification parameterization. Figures 4 and 5 show the observations of $\mathrm{NO}_{\mathrm{y}}$ (green line) and $\mathrm{NO}_{\mathrm{y}}^{*}$ derived from $\mathrm{N}_{2} \mathrm{O}$ (green dotted line) using the correlation mentioned above. The deviation between $\mathrm{NO}_{\mathrm{y}}$ and $\mathrm{NO}_{\mathrm{y}}^{*}$ from MkIV between about 500 and $650 \mathrm{~K}$ is very likely caused by denitrification. The colored lines show the corresponding CLaMS $\mathrm{NO}_{\mathrm{y}}$ mixing ratios for different parameterizations of denitrification. In Fig. 4 the nucleation rate of sedimenting the NAT particles was varied from 3.3 to $16 \times 10^{-6} \mathrm{~cm}^{-3} \mathrm{~h}^{-1}$. These results show clearly that an increase of the nucleation rate yields larger denitrification. For the reference simulation (marked blue in all figures unless otherwise stated) the nucleation rate of $7.8 \times 10^{-6} \mathrm{~cm}^{-3} \mathrm{~h}^{-1}$ yields the best agreement with observed $\mathrm{NO}_{\mathrm{y}}$ above about $500 \mathrm{~K}$. At $500 \mathrm{~K}$ and below, both larger denitrification and less re-nitrification than observed was simulated. A nucleation rate of $3.3 \times 10^{-6} \mathrm{~cm}^{-3} \mathrm{~h}^{-1}$ as was used by Carslaw et al. (2002) yields too low denitrification in our simulation (Fig. 4, light blue line).

Additionally, the dependence of denitrification on the NAT nucleation rate was investigated for the whole vortex area over the winter 2002/2003 (not shown here). The maximum difference of simulated $\mathrm{NO}_{\mathrm{y}}$ mixing ratio between simulations with the nucleation rates $7.8 \times 10^{-6}$ and $3.3 \times 10^{-6} \mathrm{~cm}^{-3} \mathrm{~h}^{-1}$ averaged over equivalent latitudes above $65^{\circ} \mathrm{N}$ was found on 16 December $(1.4 \mathrm{ppb}$ at about $550 \mathrm{~K})$. This indicates that the sensitivity with respect to the nucleation rate is not special for the observation location but typical for the whole vortex area. Later in the winter, the difference between the two simulations decreases with time, e.g. the vortex average $\mathrm{NO}_{\mathrm{y}}$ difference on 19 January peaks at $540 \mathrm{~K}$ being only $0.9 \mathrm{ppb}$. In Fig. 5 , the conditions of formation of the mode with high NAT density are varied for a nucleation rate of $7.8 \times 10^{-6} \mathrm{~cm}^{-3} \mathrm{~h}^{-1}$. The red line shows a simulation in which NAT formation from liquid aerosol is completely suppressed, the blue dotted and the orange line show simulations in which the mode with high NAT density is formed at supersaturation 30 and 10, respectively. These three simulations show almost identical denitrification at the location of the MkIV observation. This is most likely the case because supersaturations of 10 and higher are probably not reached in the history of the observed air masses.

Alternatively, the observed denitrification could be explained by using a higher nucleation rates in combination with hindering the growth of the NAT particles by the presence of a NAT mode with high particle density. This mode has been observed in December 2002 by balloon and satellite measurements (Larsen et al., 2004; Spang et al., 2005). As shown in Fig. 5, this mode cannot be obtained in this case by varying the NAT supersaturation necessary to form NAT, but it can be reached by allowing NAT formation on SAT particles.

The light blue line Fig. 5 shows a simulation with the same nucleation rate $\left(7.8 \times 10^{-6} \mathrm{~cm}^{-3} \mathrm{~h}^{-1}\right)$ in which the formation of NAT from SAT is allowed. The SAT particles in the simulation originate from previously evaporated NAT particles that remained below the melting temperature of about $215 \mathrm{~K}$. 


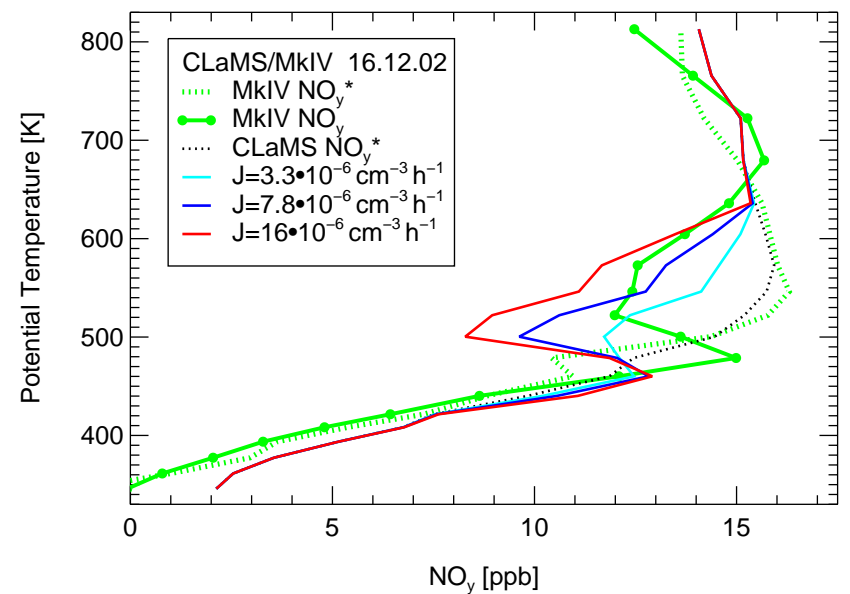

Fig. 4. $\mathrm{NO}_{\mathrm{y}}$ observation and simulations. Shown are MkIV observation of $\mathrm{NO}_{\mathrm{y}}$ (green line) and $\mathrm{NO}_{\mathrm{y}}^{*}$ derived from $\mathrm{N}_{2} \mathrm{O}$ (dotted green line) as well as CLaMS simulations for $\mathrm{NO}_{\mathrm{y}}^{*}$ (black dotted line) and $\mathrm{NO}_{\mathrm{y}}$ (colored lines) with different nucleation rates $J$ for the mode with low particle density as indicated in the legend. The CLaMS simulations are vertically averaged over the $\pm 1 \mathrm{~km}$ vertically sampled volume by MkIV.

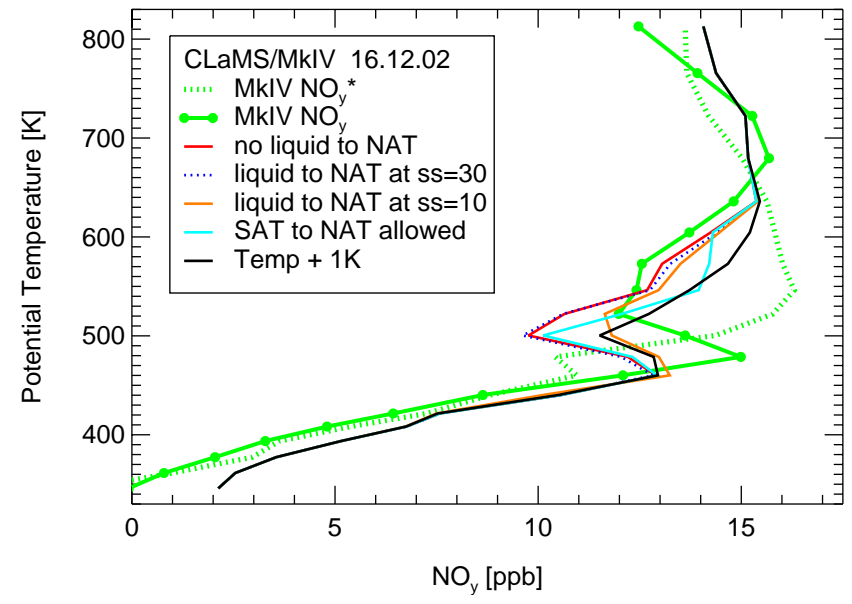

Fig. 5. As Fig. 4, but for different denitrification parameterizations. The colored lines show results of CLaMS simulations for nucleation rate of $J=7.8 \times 10^{-6} \mathrm{~cm}^{-3} \mathrm{~h}^{-1}$ and different formation assumptions for the NAT mode with high particle density. No NAT formation from liquid aerosol (red), Formation at $\mathrm{HNO}_{3}$ supersaturation over NAT of 30 (blue dotted, reference simulation) and 10 (orange), and with NAT formation from SAT in combination with a doubled nucleation rate (light blue). The black line shows a simulations as the reference simulation but with temperatures artificially increased by $1 \mathrm{~K}$.

This case yielded less denitrification, comparable to a simulation with about half the nucleation rate (compare Fig. 4). However, laboratory studies show that NAT nucleation on SAT is unlikely (Iraci et al., 1995; Koop et al., 1997). But similar results should be expected if instead of SAT other yet unknown condensation nuclei would form NAT. Therefore, the assumption of NAT nucleation on SAT is not considered further. The sensitivity with respect to temperature was also investigated. The black line in Fig. 5 shows the denitrification simulated with an artificial $1 \mathrm{~K}$ increase of the temperature in the ECMWF analysis. This of course yields less denitrification at the location of the MkIV observation. The largest impact, about 2 ppb less denitrification is seen around $500 \mathrm{~K}$. This denitrification change is comparable to a nucleation rate decrease by a factor of two.

At about $480 \mathrm{~K}$ potential temperature, the MkIV observations suggest re-nitrification that seems not to be represented in the simulation. Figure 6 a shows the simulated $\mathrm{NO}_{\mathrm{y}}$ change on the $480 \mathrm{~K}$ level. Here, the air in the vortex core is denitrified. Around this denitrified area, a filament of re-nitrified air is visible very close to the location of the MkIV observation (pink circle). Figure $6 \mathrm{~b}$ shows an enlargement of the area around the observed airmass on this level reduced to the vertical resolution of MkIV and the sampled MkIV volume ( $1 \mathrm{~km}$ radius, $300 \mathrm{~km}$ length, transformed to its 12:00 UT location) indicated by the pink line. The reason for the discrepancy could be either due to model resolution, uncertainties of wind and temperature analyses or variability within the volume sampled by MkIV. This cannot be examined in detail here.

\subsection{Comparison with Geophysica observations}

Between 15 January and 9 February, stratospheric in-situ measurements were obtained on 9 flights of the Geophysica aircraft within the scope of the VINTERSOL-EUPLEX campaign. Observations of chemically long-lived tracers can be used to validate the transport of the simulation. Figure 7 shows the comparison of HAGAR observations (Volk et al., in preparation, $2005^{1}$ ) and CLaMS simulation of the tracer $\mathrm{N}_{2} \mathrm{O}$ that can be considered as chemically inert over the winter. The left panel shows the comparison along the flight of 19 January 2003. The right panel shows a scatter plot for all $\mathrm{N}_{2} \mathrm{O}$ observations obtained between 19 January and 9 February 2003 and the corresponding CLaMS observations. There is some indication that the model over-estimates $\mathrm{N}_{2} \mathrm{O}$ for mixing ratios below about $100 \mathrm{ppb}$, but in general this comparison shows that the simulation is able to reproduce well the advection and mixing of the air masses. The reason for the slight discrepancy below $100 \mathrm{ppb} \mathrm{N}_{2} \mathrm{O}$ may be either due to uncertainties in the transport (resolution, vertical descent) or initialization.

Between 15 January and 4 February, no PSC particles are simulated by the sedimentation scheme which is expected because of the major warming in January. Therefore,

\footnotetext{
${ }^{1}$ Volk, C. M., Werner, A., Wetter, T., Ivanova, E., Wollny, A., Ulanovsky, A., Ravegnani, F., Schlager, H., Konopka, P., and Toon, G.: Ozone loss within the 2003 Arctic vortex derived from in situ observations with the Geophysica aircraft, Atmos. Chem. Phys. Discuss., in preparation, 2005.
} 

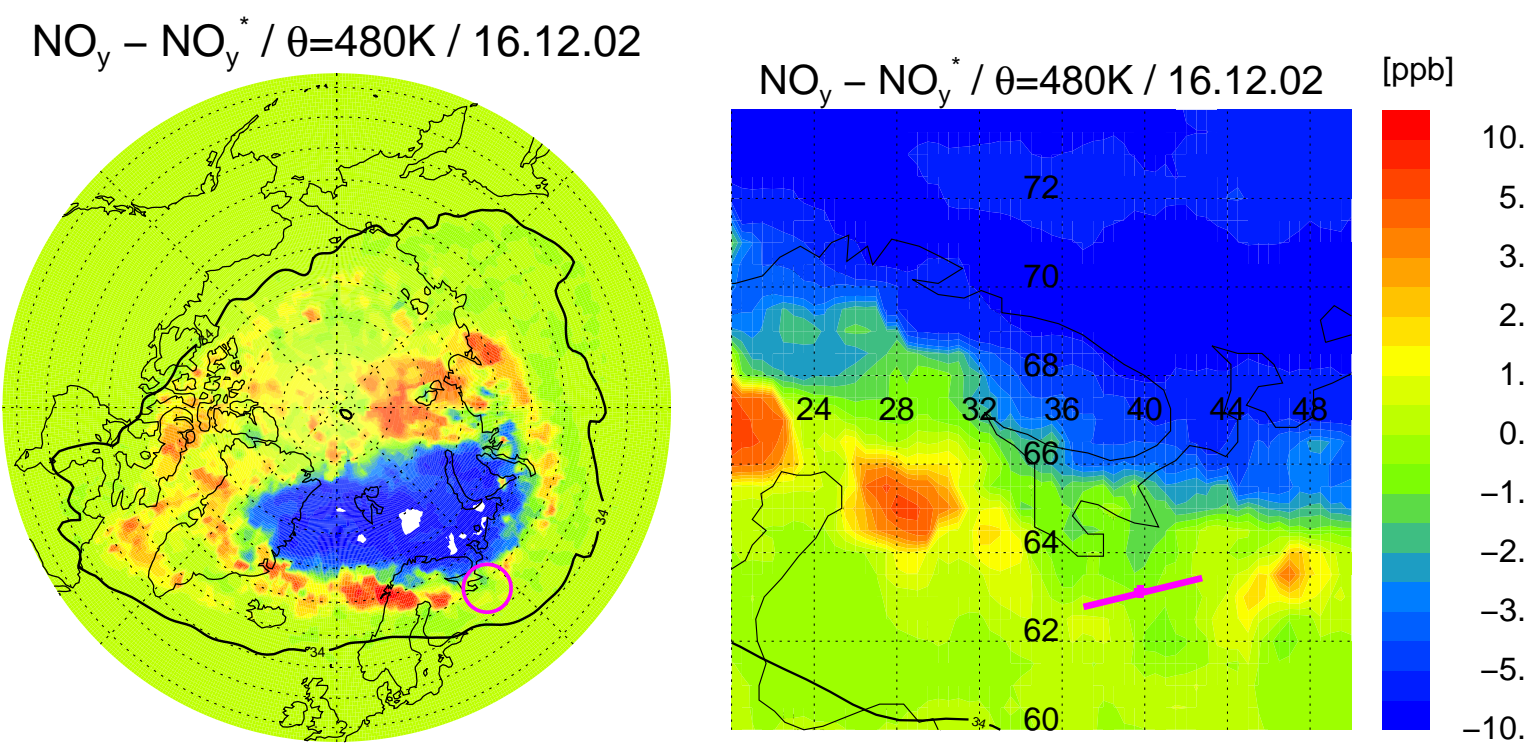

Fig. 6. Simulated redistribution of $\mathrm{NO}_{\mathrm{y}}$ on 16 December 2002 for the potential temperature level $480 \mathrm{~K}$ for CLaMS simulation with $100 \mathrm{~km}$ horizontal resolution. The left panel shows a polar stereographic projection. White areas correspond to values less than $-10 \mathrm{ppb}$. The pink circle indicates the MkIV observation point (transformed to synoptic 12:00 UT location). The black line marks the vortex edge using the vortex definition of Nash et al. (1996). The right panel shows an enlargement around the observed airmass reduced to the vertical resolution of MkIV. The volume sampled by MkIV (1 km radius and $300 \mathrm{~km}$ length) is indicated by the pink line.
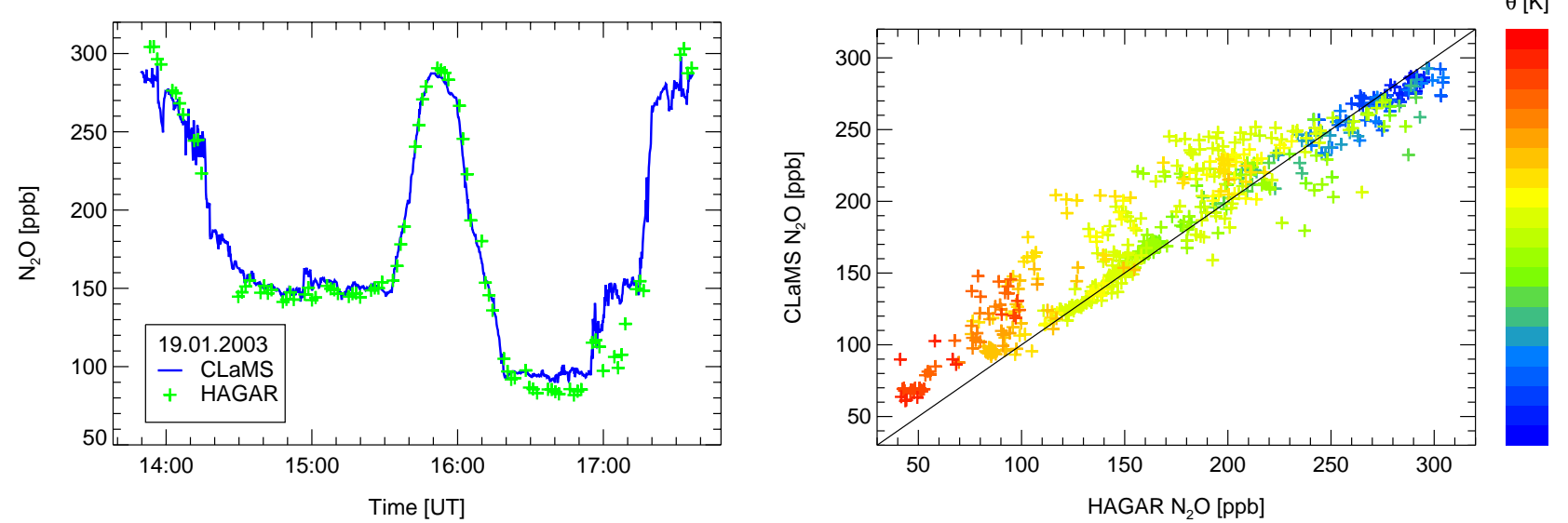

Fig. 7. Comparison of CLaMS simulations with HAGAR $\mathrm{N}_{2} \mathrm{O}$ observations. Time series for the Geophysica flight on 19 January 2003 (left). The right panel shows a one to one comparison for all flights between 19 January and 9 February 2003. The potential temperature of the observation is marked as indicated by the color bar.

no additional denitrification was simulated during this time period, but the denitrified air masses were advected. We compare the simulated denitrification with observations of denitrification determined from the difference of $\mathrm{NO}_{\mathrm{y}}$ measured by the SIOUX instrument (Schlager et al., in preparation, 2005²; Voigt et al., 2005) and $\mathrm{NO}_{\mathrm{y}}^{*}$ derived from the

\footnotetext{
${ }^{2}$ Schlager, H., Voigt, C., Volk, M., Davies, S., Carslaw, K., Konopka, P., Roiger, A., and Stock, P.: Observations of denitrification and renitrification in the 2002-2003 Arctic winter stratosphere, Atmos. Chem. Phys. Discuss., in preparation, 2005.
}

HAGAR $\mathrm{N}_{2} \mathrm{O}$ measurements shown above without having to consider $\mathrm{HNO}_{3}$ in the particle phase at these temperatures. Figure 8 shows in the top panel the altitude dependence of vertical $\mathrm{NO}_{\mathrm{y}}$ redistribution for the parts of the flight of 19 January within the polar vortex (equivalent latitude $>70^{\circ}$ ). The shape of the denitrification and re-nitrification profile is reproduced well. The absolute values are underestimated for both nucleation rates $J=3.3 \times 10^{-6} \mathrm{~cm}^{-3} \mathrm{~h}^{-1}$ and for $J=7.8 \times 10^{-6} \mathrm{~cm}^{-3} \mathrm{~h}^{-1}$. The larger nucleation rate results in stronger denitrification and renitrification and the 

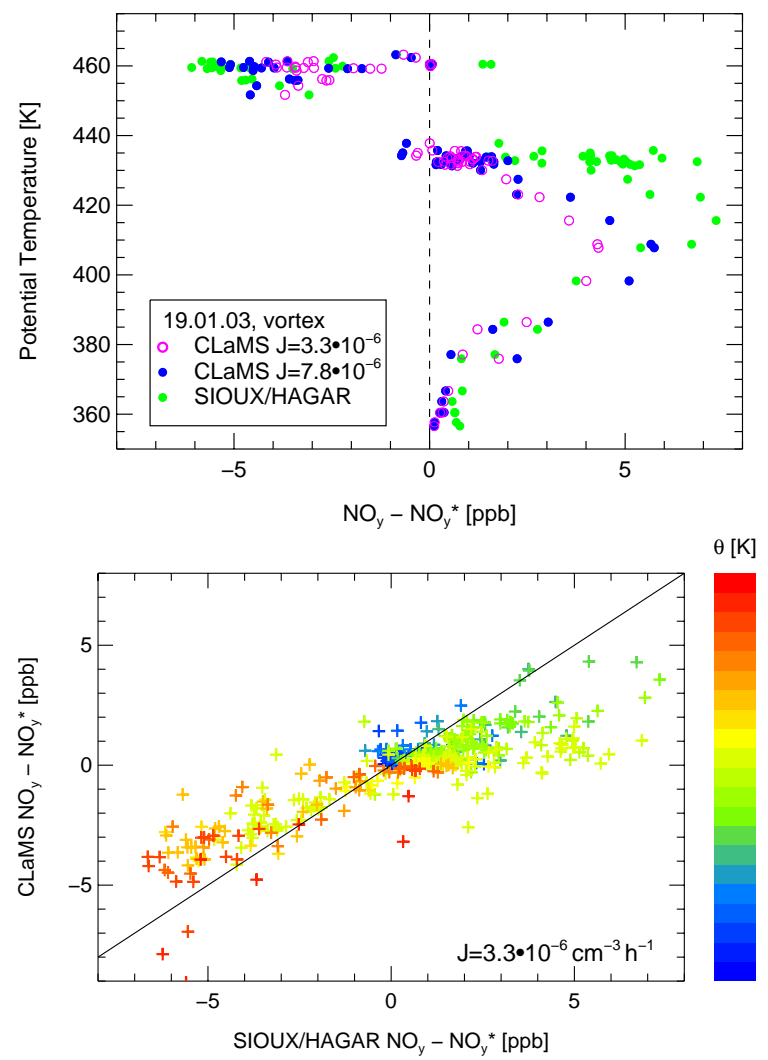

500.

485.

470.

455

440.

425.

410.

395.

380.

365.

350

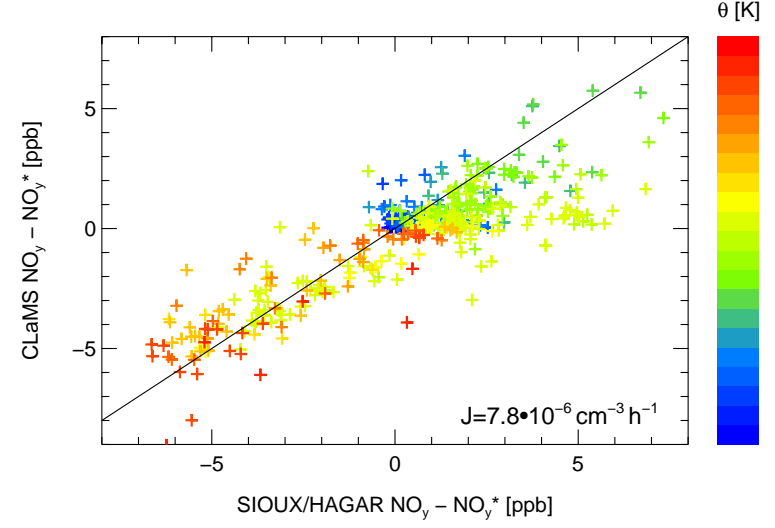

500

485.

470.

455 .

440.

425.

410.

395.

380.

365.

350

Fig. 8. Comparison of denitrification from CLaMS simulation with that derived from SIOUX and HAGAR observations. The lower panels show the altitude profile within the polar vortex core (equivalent latitude $>70^{\circ}$ ). Only the CLaMS data directly corresponding to the observations are shown. Blue circles correspond to the reference simulation with the nucleation rate $J=7.8 \times 10^{-6} \mathrm{~cm}^{-3} \mathrm{~h}^{-1}$ and the pink open circles to the simultion with the nucleation rate $J=3.3 \times 10^{-6} \mathrm{~cm}^{-3} \mathrm{~h}^{-1}$. The middle and bottom panels show the one to one comparison for all flights between 19 January and 9 February for these two nucleation rates. The potential temperature of the observation is marked as indicated by the color bar.

results agrees better with the observations. Both, observations and the simulation do show the turnover level from denitrification to re-nitrification at about $440 \mathrm{~K}$ at that time. The northward part of the flight on 19 January was flown

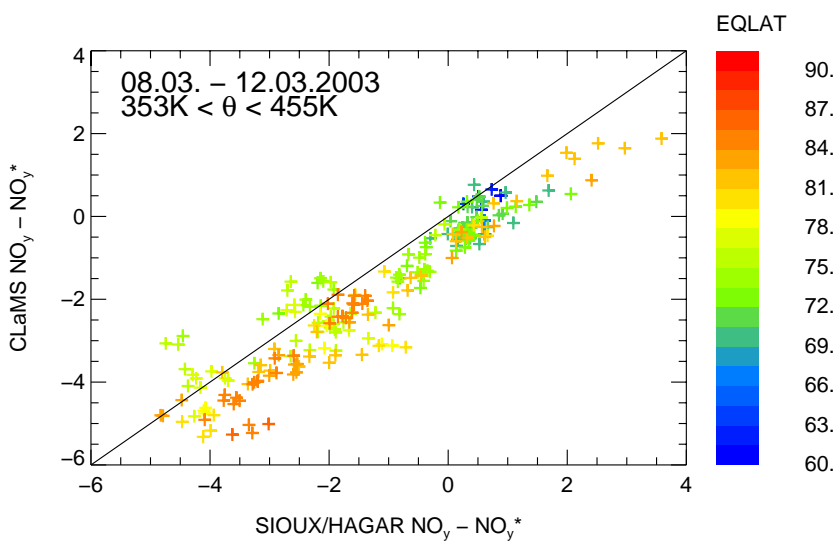

Fig. 9. Comparison of $\mathrm{NO}_{\mathrm{y}}-\mathrm{NO}_{\mathrm{y}}^{*}$ simulated by CLaMS using a nucleation rate of $J=7.8 \times 10^{-6} \mathrm{~cm}^{-3} \mathrm{~h}^{-1}$ and derived from SIOUX and HAGAR observations on Geophysica on 8 and 12 March 2003 for equivalent latitudes above $60^{\circ} \mathrm{N}$. The color of the symbols denotes the equivalent latitude of the observation location.

around that $440 \mathrm{~K}$ level. At this level CLaMS underestimates the re-nitrification.

The bottom two panels of Fig. 8 show the comparison for all observations between 19 January and 9 February 2003 for both choices of the nucleation rate. The results are similar for both nucleation rates. While for both cases the renitrification is under-estimated by the simulation, the reference simulation with $J=7.8 \times 10^{-6} \mathrm{~cm}^{-3} \mathrm{~h}^{-1}$ does agree better with the observations of denitrified air masses above about $440 \mathrm{~K}$. The reason for the similar results using the different nucleation rates is a saturation effect. Since less $\mathrm{HNO}_{3}$ is available in denitrified air, the threshold temperature for NAT formation is lowered and therefore additional denitrification is hindered. Therefore, the simulated vertical $\mathrm{NO}_{\mathrm{y}}$ redistribution depends significantly on the assumed particle nucleation rate most notably in early winter shortly after the onset of PSCs.

Also, the reference simulation was continued until midMarch. In March, the denitrification is still well simulated. Figure 9 shows the comparison of simulated $\mathrm{NO}_{\mathrm{y}}-$ $\mathrm{NO}_{\mathrm{y}}^{*}$ with denitrification derived from SIOUX and HAGAR for the flights on 8 March and 12 March for equivalent latitudes poleward $60^{\circ} \mathrm{N}$ during the ENVISAT validation campaign. Here there is still reasonable agreement with the hint of a larger denitrification and lower re-nitrification in the simulation. The average difference of $\mathrm{NO}_{\mathrm{y}}-\mathrm{NO}_{\mathrm{y}}^{*}( \pm 1 \sigma)$ between simulation and observations in March is $-0.6 \pm 0.6 \mathrm{ppb}$. Unlike the comparion in January and early February, the simulation with the lower nucleation rate $J=3.3 \times 10^{-6} \mathrm{~cm}^{-3} \mathrm{~h}^{-1}$ does agree better with the observations in March $(-0.2 \pm 0.7 \mathrm{ppb}$, not shown). 


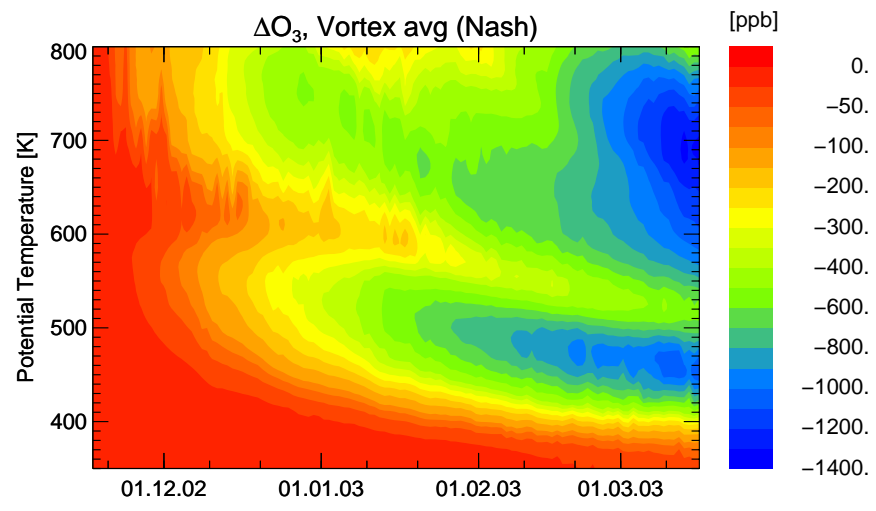

Fig. 10. Simulated ozone loss as function of time and potential temperature. Shown is the vortex average using the vortex definition of Nash et al. (1996) for the period 17 November 2002 to 16 March 2003.

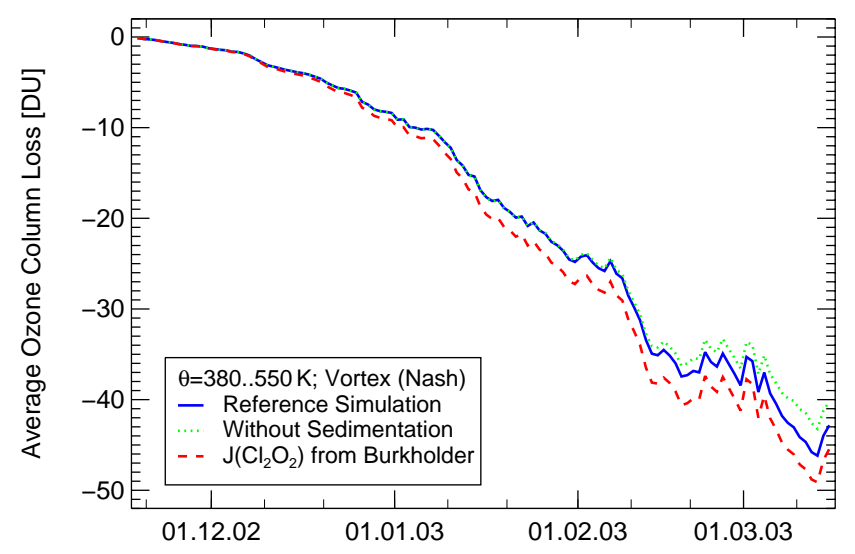

Fig. 11. Simulated vortex average column ozone loss between 380 and $550 \mathrm{~K}$ potential temperature. The blue line corresponds to the reference simulation. The green dotted line corresponds to a simulations without sedimentation. The red dashed line corresponds to a simulation in which the absorption cross sections of $\mathrm{Cl}_{2} \mathrm{O}_{2}$ are taken from Burkholder et al. (1990).

\section{Simulated ozone depletion}

To investigate the ozone depletion in the winter 2002/2003, the simulation was continued until mid-March in order to include the second period of low stratospheric temperatures in mid-February. The chemical ozone depletion was determined by the difference between model ozone and an artificial passive ozone tracer. This tracer was initialized on 17 November identically as ozone, was advected and mixed as all other chemical species but did not undergo any chemical change. The simulated ozone depletion averaged over the vortex as defined by Nash et al. (1996) as function of time and potential temperature is shown in Fig. 10. The simulations indicate that vortex average ozone depletion reaches about $1.1 \mathrm{ppm}$ in mid-March around the $460 \mathrm{~K}$ level.

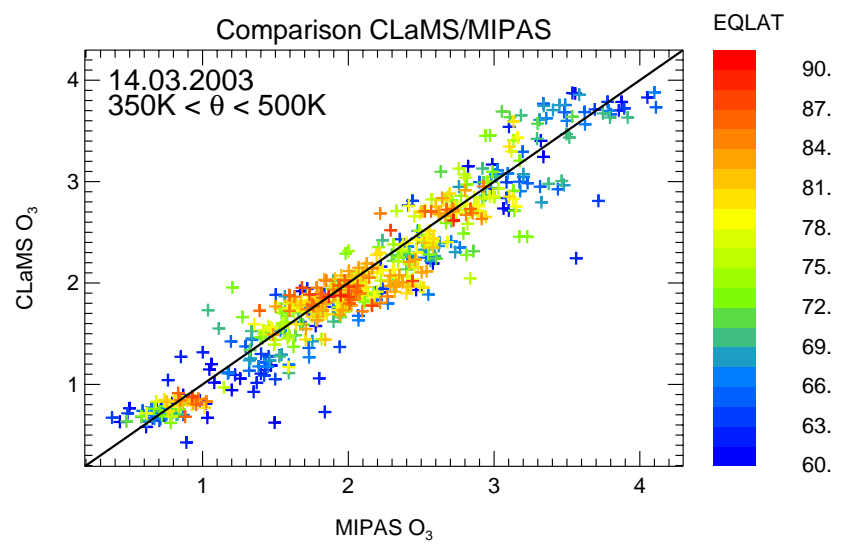

Fig. 12. Comparison of ozone mixing ratios simulated by CLaMS and observed by MIPAS for potential temperatures between $350 \mathrm{~K}$ and $500 \mathrm{~K}$ on 14 March 2003. The color of the symbols denotes the equivalent latitude of the observation location.

In Fig. 11 the simulated ozone column loss between $380 \mathrm{~K}$ and $550 \mathrm{~K}$ averaged over the vortex after Nash et al. (1996) is shown for the reference simulation (blue line) and different sensitivity simulations (see below). The simulated vortex average ozone column loss on 13 March between $380 \mathrm{~K}$ and $550 \mathrm{~K}$ was 46 Dobson units (21\% of the partial ozone column), and between $350 \mathrm{~K}$ and $900 \mathrm{~K}$ it was 68 Dobson units $(18 \%)$.

To verify that the ozone depletion was simulated correctly over the winter, the simulated ozone mixing ratios were compared with observations of ozone on 14 March 2003 made by MIPAS-ENVISAT. On that day, MIPAS data did have a good coverage of the polar vortex. Figure 12 shows the one to one comparison for MIPAS observations between 350 and $500 \mathrm{~K}$ potential temperature and for equivalent latitudes poleward of $60^{\circ} \mathrm{N}$. The differences between simulation and observations can be explained by small-scale structures below the resolution of CLaMS and the accuracy of the MIPAS $\mathrm{O}_{3}$ observations of about 10\% (Blumenstock et al., 2003). The average difference $( \pm 1 \sigma)$ between simulated and observed ozone mixing ratios (CLaMS-MIPAS) is $-0.06 \pm 0.24 \mathrm{ppm}$. The largest differences in the comparison occur at the edge and outside the vortex, for equivalent latitudes equatorward of $70^{\circ} \mathrm{N}$. Figure 13 shows ozone comparisons with the FOX instrument (Schlager et al., in preparation, $2005^{2}$ ) on board the Geophysica aircraft made during the Envisat validation campaign between 28 February and 16 March. Here the average difference (CLaMS-FOX) is also low $-0.08 \pm 0.20 \mathrm{ppm}$. This indicates that all significant ozone loss processes in the vortex have been covered by the simulation.

The magnitude of the ozone depletion is comparable with estimates derived from HALOE data using the tracer correlation method (Tilmes et al., 2003), but the altitude of the maximum ozone depletion is about $25 \mathrm{~K}$ higher in the simulation. 


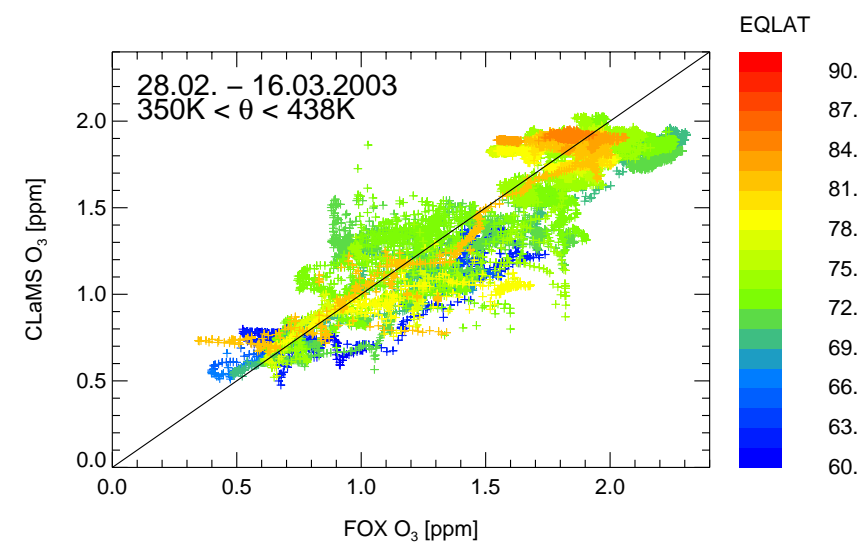

Fig. 13. Comparison of ozone mixing ratios simulated by CLaMS and observed by FOX on Geophysica between 28 February and 16 March 2003, The color of the symbols denotes the equivalent latitude of the observation location.

Goutail et al. (2005) report a slightly higher amount of ozone depletion, $23 \%$ of the total column derived from observations SAOZ UV-visible spectrometers and CTM passive ozone simulations. However, due to the different altitude range the results are not completely comparable.

To compare with the results of the SLIMCAT model (Feng et al., 2005), one has to take into account that they use absorption cross section of the photolysis of $\mathrm{Cl}_{2} \mathrm{O}_{2}$ by Burkholder et al. (1990) extrapolated to the wavelength of $450 \mathrm{~nm}$ instead of those recommended by Sander et al. (2003) that were used here. Therefore sensitivity simulations were carried out with the Burkholder et al. (1990) absorption cross section which leads to more ozone depletion.

Compared with the reference simulation (blue line in Fig. 11), the ozone column loss increased due to the photolysis of $\mathrm{Cl}_{2} \mathrm{O}_{2}$ by Burkholder et al. (1990) by about 2 Dobson units by mid January and did not increase significantly further to values between 2.5 and 3 Dobson units in late February and March (red dashed line in Fig. 11 compared with blue line). This corresponds to an increase of the column ozone depletion between $380 \mathrm{~K}$ and $550 \mathrm{~K}$ relative to the reference simulation of at most $11.2 \%$ on 14 January. At 15 March this corresponds to $6.1 \%$ more ozone depletion compared to the reference simulation. Feng et al. (2005) show the partial ozone column loss between $345 \mathrm{~K}$ and $670 \mathrm{~K}$ averaged for the area poleward of $65^{\circ} \mathrm{N}$ equivalent latitude. The time development of the simulated column ozone loss in our simulation $(350 \mathrm{~K}-670 \mathrm{~K})$ is very similar. Due to different dynamics and resolution, there is different variability from day to day. The average difference between the simulated ozone column losses in February (1-16 March) is $1.5 \pm 4.0$ Dobson units (3.5 \pm 4.1 Dobson units), where SLIMCAT simulates slightly lower column ozone loss. These small deviations are due to different resolution, tranport schemes and a simplified denitrification scheme in SLIMCAT (Davies et al., 2003) that was tested and optimized only for a cold winter.
Further, the impact of denitrification on the simulated ozone depletion was investigated through an additional simulation in which the sedimentation scheme was deactivated (green dotted line in Fig. 11). In general, the simulated ozone depletion is very similar to the reference simulation. The largest effect of the denitrification was found towards the end of the simulation when the deactivation of active chlorine species is hindered by less available $\mathrm{NO}_{\mathrm{x}}$ due to denitrification. The maximum of the ozone depletion due to denitrification averaged over the vortex as defined by Nash et al. (1996) was determined for 16 March to be $149 \mathrm{ppb}$ at $455 \mathrm{~K}$ potential temperature level corresponding to $14 \%$ of the ozone depletion of the reference simulation. The column ozone loss in the $380-550 \mathrm{~K}$ range attributed to denitrification is $3.1 \mathrm{DU}$ (7\% of the partial column) .

Another striking feature is the simulated ozone depletion above the $600 \mathrm{~K}$ level. Unlike the levels below about $500 \mathrm{~K}$ where ozone loss is mainly caused by catalytic cycles involving chlorine and bromine compounds, no PSCs and no chlorine activation are simulated at these altitudes. The reason for the ozone depletion above $600 \mathrm{~K}$ are catalytic cycles involving $\mathrm{NO}_{\mathrm{x}}$. Especially in the winter 2002/2003, that was dynamically active, the time when vortex air was exposed to sunlight began earlier and was longer than in other winters. Therefore, also the typical summer ozone depletion started earlier. Such a behavior was also observed in the dynamically active 2002 Antarctic winter (Grooß et al., 2005).

The chemical ozone depletion inside the vortex at altitudes above $600 \mathrm{~K}$ was also found in the comparison of a high resolution CLaMS tracer simulation and MIPAS observations (Konopka et al., in preparation, $2005^{3}$ ). A similar comparison as above with MIPAS data on 14 March 2003 between $500 \mathrm{~K}$ and $800 \mathrm{~K}$ yields a mean difference (CLaMSMIPAS) of $+0.27 \pm 0.44 \mathrm{ppm}$. That means the simulation slightly under-estimates the ozone depletion in that altitude range.

\section{Conclusions}

A Lagrangian module for single particle growth and advection was developed and integrated in the Chemical Lagrangian Model of the Stratosphere (CLaMS). With this model, the vertical redistribution of $\mathrm{NO}_{\mathrm{y}}$ for the winter 2002/2003 was successfully simulated. The presented simulations demonstrate that choosing a nucleation rate of $J=7.8 \times 10^{-6} \mathrm{~cm}^{-3} \mathrm{~h}^{-1}$ results in the best reproduction of the observed $\mathrm{NO}_{\mathrm{y}}$ in mid-December 2002. For that time period shortly after the onset of PSCs, the simulated denitrification is most sensitive to the nucleation rate in the absence of the mode with high particle density. It has been also shown that

\footnotetext{
${ }^{3}$ Konopka, P., Grooß, J.-U., Müller, R., et al.: Halogen- versus NOx-induced ozone loss in the Arctic middle stratosphere during the 2002/03 winter and spring, Atmos. Chem. Phys. Discuss., in preparation, 2005.
} 
the presence of the mode with high particle density (Larsen et al., 2004; Spang et al., 2005) decelerates the growth of the large NAT particles. Thus, in the presence of higher NAT particle number densities, the nucleation rate has to be increased to achieve similar results. Later in the winter in midJanuary to early February, the simulated denitrification does not significantly depend on the nucleation rate.

Further, the simulated ozone loss over the simulation period was determined. By mid-March the vortex averaged ozone loss around $460 \mathrm{~K}$ was about $1.1 \mathrm{ppm}$ comparable to other ozone loss estimates for this winter. The corresponding column ozone loss between 380 and $550 \mathrm{~K}$ was determined to be 46 Dobson units ( $21 \%$ of the partial ozone column). A sensitivity simulation showed that $14 \%$ of the vortex ozone loss on the $455 \mathrm{~K}$ level (corresponding to $7 \%$ ozone column depletion between 380 and $550 \mathrm{~K}$ ) can be attributed to denitrification. At higher altitudes above $600 \mathrm{~K}$ also significant ozone loss was determined. This loss was caused by $\mathrm{NO}_{\mathrm{x}}{ }^{-}$ catalyzed ozone loss cycles in vortex air masses with large exposure to sunlight.

Acknowledgements. The authors thank B. Luo and T. Deshler for fruitful discussions. The European Centre for Medium-Range Weather Forecasts (ECMWF) provided meteorological analyses and forecasts during campaign that were very helpful for flight planning. The European Space Agency (ESA) provided the ENVISAT-MIPAS data. We thank R. Spang for extracting the MIPAS data and providing the cloud index data and W. Feng for providing his ozone column loss data. Excellent programming support was provided by N. Thomas in the development of the sedimentation module and by B. Deutsch in porting the programs to a parallel computer. Part of the simulations were performed on the Jülich Multi Processor (JUMP). This work was funded by the EU within the VINTERSOL-EUPLEX project.

Edited by: K. Carslaw

\section{References}

Becker, G., Grooß, J.-U., McKenna, D. S., and Müller, R.: Stratospheric photolysis frequencies: Impact of an improved numerical solution of the radiative transfer equation, J. Atmos. Chem., 37, 217-229, 2000

Blumenstock, T., Griesfeller, A., Hase, F., Schneider, M., Boyd, I., Caliesi, Y., Godin, S., Koopmann, R., Lambert, J.-C., Soebijanta, V., Swart, D., Raffalski, U., Schets, H., De Muer, D., Stebel, K., Steinbrecht, W., and Stubi, R.: Comparison of MIPAS $\mathrm{O}_{3}$ profiles with ground-based measurements, in Proceedings of Envisat validation workshop 3-13 December 2002, ESA-SP-531, Frascati, Italy, 2003.

Burkholder, J. B., Orlando, J. J., and Howard, C. J.: Ultraviolet absorption cross section of $\mathrm{Cl}_{2} \mathrm{O}_{2}$ between 210 and $410 \mathrm{~nm}, \mathrm{~J}$. Phys. Chem., 94, 687-695, 1990.

Carslaw, K. S., Luo, B. P., and Peter, T.: An analytical expression for the composition of aqueous $\mathrm{HNO}_{3}-\mathrm{H}_{2} \mathrm{SO}_{4}-\mathrm{H}_{2} \mathrm{O}$ stratospheric aerosols including gas phase removal of $\mathrm{HNO}_{3}$, Geophys. Res. Lett., 22, 1877-1880, 1995.
Carslaw, K. S., Kettleborough, J. A., Northway, M. J., Davies, S., Gao, R., Fahey, D. W., Baumgardner, D. G., Chipperfield, M. P., and Kleinböhl, A.: A vortex-scale simulation of the growth and sedimentation of large nitric acid hydrate particles,J. Geophys. Res., 107, doi:10.1029/2001JD000467, 2002.

Davies, S., Chipperfield, M. P., Carslaw, K. S., Sinnhuber, B.-M., Anderson, J. G., Stimpfle, R. M., Wilmouth, D. M., Fahey, D. W., Popp, P. J., Richard, E. C., von der Gathen, P., Jost, H., and Webster, C. R.: Modeling the effect of denitrification on Arctic ozone depletion during winter 1999/2000, J. Geophys. Res., 108, doi:10.1029/2001JD000445, 2003.

Deshler, T., Larsen, N., Weissner, C., Schreiner, J., Mauersberger, K., Cairo, F., Adriani, A., Di Donfrancesco, G., Ovarlez, J., Ovarlez, H., Blum, U., Fricke, K. H., and Dörnbrack, A.: Large nitric acid particles at the top of an Arctic stratospheric cloud, J. Geophys. Res., 108, 4517, doi:10.1029/2003JD003479, 2003.

Fahey, D. W., Kelly, K. K., Kawa, S. R., Tuck, A. F., Loewenstein, M., Chan, K. R., and Heid, L. E.: Observations of denitrification and dehydration in the winter polar stratosphere, Nature, 344 321-324, 1990.

Fahey, D. W., Gao, R. S., Carslaw, K. S., Kettleborough, J., Popp, P. J., Northway, M. J., Holecek, J. C., Ciciora, S. C., McLaughlin, R. J., Thompson, T. L., Winkler, R. H., Baumgardner, D. G., Gandrud, B., Wennberg, P. O., Dhaniyala, S., McKinley, K., Peter, T., Salawitch, R. J., Bui, T. P., Elkins, J. W., Webster, C. R., Atlas, E. L., Jost, H., Wilson, J. C., Herman, R. L., Kleinböhl, A., and von König, M.: The detection of large $\mathrm{HNO}_{3}$-containing particles in the winter Arctic stratosphere, Science, 291, 10261031, 2001.

Feng, W., Chipperfield, M. P., Davies, S., Sen, B., Toon, G., Blavier, J. F., Webster, C. R., Volk, C. M., Ulanovsky, A., Ravegnani, F., von der Gathen, P., Jost, H., Richard, E. C., and Claude, H.: Three-dimensional model study of the Arctic ozone loss in 2002/2003 and comparison with 1999/2000 and 2003/2004, Atmos. Chem. Phys., 5, 139-152, 2005,

SRef-ID: 1680-7324/acp/2005-5-139.

Fueglistaler, S., Luo, B. P., Voigt, C., Carslaw, K. S., and Peter, T.: NAT-rock formation by mother clouds: a microphysical model study, Atmos. Chem. Phys., 2, 93-98, 2002,

SRef-ID: 1680-7324/acp/2002-2-93.

Goutail, F., Pommereau, J.-P., Lefèvre, F., Roozendael, M. V., Andersen, S. B., Kåstad-Høiskar, B.-A., Dorokhov, V., Kyrö, E., Chipperfield, M. P., and Feng, W.: Early unusual ozone loss during the Arctic winter 2002/2003 compared to other winters, Atmos. Chem. Phys., 5, 665-677, 2005, SRef-ID: 1680-7324/acp/2005-5-665.

Grooß, J.-U.: Modelling of Stratospheric Chemistry based on HALOE/UARS Satellite Data, PhD thesis, University of Mainz, 1996.

Grooß, J.-U. and Russell, J. M.: Technical note: A stratospheric climatology for $\mathrm{O}_{3}, \mathrm{H}_{2} \mathrm{O}$ and $\mathrm{CH}_{4}$ derived from HALOE measurements, Atmos. Chem. Phys. Discuss., 5, 2973-2988, 2005, SRef-ID: 1680-7375/acpd/2005-5-2973.

Grooß, J.-U., Günther, G., Konopka, P., Müller, R., McKenna, D. S., Stroh, F., Vogel, B., Engel, A., Müller, M., Hoppel, K., Bevilacqua, R., Richard, E., Webster, C. R., Elkins, J. W., Hurst, D. F., Romashkin, P. A., and Baumgardner, D. G.: Simulation of ozone depletion in spring 2000 with the Chemical Lagrangian Model of the Stratosphere (CLaMS), J. Geophys. Res., 
107, 8295, doi:10.1029/2001JD000456, 2002.

Grooß, J.-U., Konopka, P., and Müller, R.: Ozone chemistry during the 2002 Antarctic vortex split, J. Atmos. Sci., 62, 860-870, 2005.

Hanson, D. R. and Mauersberger, K.: Laboratory studies of the nitric acid trihydrate: Implications for the south polar stratosphere, Geophys. Res. Lett., 15, 855-858, 1988.

Iraci, L. T., Middlebrook, A. M., and Tolbert, M. A.: Laboratory studies of the formation of polar stratospheric clouds: Nitric acid condensation on thin sulfuric acid films, J. Geophys. Res., 100, 20 969-20 977, 1995.

Konopka, P., Steinhorst, H.-M., Grooß, J.-U., Günther, G., Müller, R., Elkins, J. W., Jost, H.-J., Richard, E., Schmidt, U., Toon, G., and McKenna, D. S.: Mixing and ozone loss in the 1999-2000 Arctic vortex: Simulations with the 3-dimensional Chemical Lagrangian Model of the Stratosphere (CLaMS), J. Geophys. Res., 109, D02315, doi:10.1029/2003JD003792, 2004.

Koop, T., Carslaw, K. S., and Peter, T.: Thermodynamic stability and phase transitions of PSC particles, Geophys. Res. Lett., 24, 2199-2202, 1997.

Larsen, N., Knudsen, B. M., Svendsen, S. H., Deshler, T., Rosen, J. M., Kivi, R., Weisser, C., Schreiner, J., Mauersberger, K., Cairo, F., Ovarlez, J., Oelhaf, H., and Spang, R.: Formation of solid particles in synoptic-scale Arctic PSCs in early winter 2002/2003, Atmos. Chem. Phys., 4, 2001-2013, 2004,

\section{SRef-ID: 1680-7324/acp/2004-4-2001.}

Luo, B. P., Voigt, C., Fueglistaler, S., and Peter, T.: Extreme NAT supersaturations in mountain wave ice PSCs: A clue to NAT formation, J. Geophys. Res., 108, 4443, doi:10.1029/2002JD003104, 2003.

Mann, G. W., Davies, S., Carslaw, K. S., Chipperfield, M. P., and Kettleborough, J.: Polar vortex concentricity as a controlling factor in Arctic denitrification, J. Geophys. Res., 107, 4663, doi:10.1029/2002JD002102, 2002.

Mann, G. W., Davies, S., Carslaw, K. S., and Chipperfield, M. P.: Factors controlling Arctic denitrification in cold winters of the 1990s, Atmos. Chem. Phys., 3, 403-416, 2003 ,

SRef-ID: 1680-7324/acp/2003-3-403.

McKenna, D. S., Grooß, J.-U., Günther, G., Konopka, P., Müller, R., Carver, G., and Sasano, Y.: A new Chemical Lagrangian Model of the Stratosphere (CLaMS): Part II Formulation of chemistry-scheme and initialisation, J. Geophys. Res., 107, 4309, doi:10.1029/2000JD000114, 2002a.

McKenna, D. S., Konopka, P., Grooß, J.-U., Günther, G., Müller, R., Spang, R., Offermann, D., and Orsolini, Y.: A new Chemical Lagrangian Model of the Stratosphere (CLaMS): Part I Formulation of advection and mixing, J. Geophys. Res., 107, 4256, doi:10.1029/2000JD000113, 2002b.

Nash, E. R., Newman, P. A., Rosenfield, J. E., and Schoeberl, M. R.: An objective determination of the polar vortex using Ertel's potential vorticity, J. Geophys. Res., 101, 9471-9478, 1996.

Naujokat, B. and Grunow, K.: The stratospheric arctic winter 2002/03: Balloon flight planning by trajectory calculation., in: Proceedings of the 16th ESA Symposium on European Rocket and Balloon Programmes and Related Research, ESA SP-530, pp. 421-425, St. Gallen, 2003.
Popp, P. J., Northway, M. J., Holecek, J. C., Gao, R. S., Fahey, D. W., Elkins, J. W., Hurst, D. F., Romashkin, P. A., Toon, G. C., Sen, B., Schauffler, S. M., Salawitch, R. J., Webster, C. R., Herman, R. L., Jost, H., Bui, T. B., Newman, P. A., and Lait, L. R.: Severe and extensive denitrification in the 1999-2000 Arctic winter stratosphere, Geophys. Res. Lett., 28, 2875-2878, 2001.

Russell, J. M., Gordley, L. L., Park, J. H., Drayson, S. R., Tuck, A. F., Harries, J. E., Cicerone, R. J., Crutzen, P. J., and Frederick, J. E.: The Halogen Occultation Experiment, J. Geophys. Res., 98, 10777-10797, 1993.

Sander, S. P., Friedl, R. R., Golden, D. M., Kurylo, M. J., Huie, R. E., , Orkin, V. L., Moortgat, G. K., Ravishankara, A. R., Kolb, C. E., Molina, M. J., and Finlayson-Pitts, B. J.: Chemical kinetics and photochemical data for use in atmospheric studies, Evaluation number 14, JPL Publication 02-25, 2003.

Spang, R., Remedios, J. J., Kramer, L. J., Poole, L. R., Fromm, M. D., Müller, M., Baumgarten, G., and Konopka, P.: Polar stratospheric cloud observations by MIPAS on ENVISAT: Detection method, validataion and analysis of the Northern hemisphere winter 2002/2003, Atmos. Chem. Phys., 5, 679-692, 2005, SRef-ID: 1680-7324/acp/2005-5-679.

Tabazadeh, A., Djikaev, Y. S., Hamill, P., and Reiss, H.: Laboratory evidence for surface nucleation of solid Polar Stratospheric Cloud particles, J. Phys. Chem. A, 106, 10 238-10 246, 2002.

Tilmes, S., Müller, R., Grooß, J.-U., Höpfner, M., Toon, G. C., and Russell, J. M.: Very early chlorine activation and ozone loss in the Arctic winter 2002-2003, Geophys. Res. Lett., 30, 2201, doi:10.1029/2003GL018079, 2003.

Toon, G. C., Blavier, J.-F., Sen, B., Margitan, J. J., Webster, C. R., May, R. D., Fahey, D., Gao, R., Del Negro, L., Proffitt, M., Elkins, J. W., Romashkin, P. A., Hurst, D. F., Oltmans, S., Atlas, E., Schauffler, S., Flocke, F., Bui, T. P., Stimpfle, R. M., Bonne, G. P., Voss, P. B., and Cohen, R. C.: Comparison of MkIV balloon and ER-2 aircraft measurements of atmospheric trace gases, J. Geophys. Res., 104, 26 779-26790, 1999.

Voigt, C., Larsen, N., Deshler, T., Kröger, C., Schreiner, J., Mauersberger, K., Luo, B., Adriani, A., Cairo, F., Di Donfrancesco, G., Ovarlez, J., Ovarlez, H., Dörnbrack, A., Knudsen, B., and Rosen, J.: In situ mountain-wave polar stratospheric cloud measurements: Implications for nitric acid trihydrate formation, J. Geophys. Res., 108, 8331, doi:10.1029/2001JD001185, 2003.

Voigt, C., Schlager, H., Luo, B., Dörnbrack, A., Roiger, A., Stock, P., Curtius, J., Vössing, H., Borrmann, S., Davies, S., Konopka, P., Schiller, C., Shur, G., and Peter, T.: Nitric acid trihydrate (NAT) formation at low NAT supersaturation in the stratosphere, Atmos. Chem. Phys., 5, 1371-1380, 2005,

SRef-ID: 1680-7324/acp/2005-5-1371.

Waibel, A. E., Peter, T., Carslaw, K. S., Oelhaf, H., Wetzel, G., Crutzen, P. J., Pöschl, U., Tsias, A., Reimer, E., and Fischer, H.: Arctic ozone loss due to denitrification, Science, 283, 20642069, 1999. 